\section{$\underset{\substack{\text { hommes } \\ \text { \& migrations }}}{ }$}

\section{Hommes \& migrations}

Revue française de référence sur les dynamiques

migratoires

1319 | 2017

Réfugiés et migrants au Liban

\title{
Négar Djavadi, lauréate du prix de la Porte Dorée 2017
}

\section{Marie Poinsot}

\section{(2) OpenEdition}

\section{Journals}

Édition électronique

URL : http://journals.openedition.org/hommesmigrations/4018

DOI : 10.4000/hommesmigrations.4018

ISSN : 2262-3353

\section{Éditeur}

Musée national de l'histoire de l'immigration

\section{Édition imprimée}

Date de publication : 1 octobre 2017

Pagination : 189-190

ISBN : 978-2-919040-39-1

ISSN : $1142-852 X$

\section{Référence électronique}

Marie Poinsot, « Négar Djavadi, lauréate du prix de la Porte Dorée 2017 », Hommes \& migrations [En ligne], 1319 | 2017, mis en ligne le 01 octobre 2017, consulté le 07 janvier 2021. URL : http:// journals.openedition.org/hommesmigrations/4018; DOI : https://doi.org/10.4000/ hommesmigrations.4018 


\section{NÉGAR DJAVADI, LAUREATE DU PRIX DE LA PORTE DORÉE 2017}

"Recevoir le Prix de la Porte Dorée a été un grand moment d'émotion et un grand honneur. C'est un prix généreux, engagé, politique, et indispensable. De fait, avant même d'être reconnaissante d'avoir être choisie comme lauréate, je suis reconnaissante que ce prix existe, qu'il permette, par la richesse de sa sélection, de mettre en lumière aussi bien la réalité de la France d'aujourd'hui que l'héritage singulier de l'immigration, transmis à travers les livres, grâce à cette langue que nous partageons tous, quelle que soit nos origines. Je me reconnais d'autant plus dans son message, dans son désir d'allier l'exil et la littérature, que je suis née "ailleurs". D’où sans doute l'impression de recevoir bien plus qu'un prix... »

Entretien réalisé par MARIE POINSOT.

Hommes \& Migrations : Pouvez-vous nous rappeler l'histoire de votre roman Désorientale (éd. Liana Lévi, 2017) ?

Négar Djavadi : Désorientale est une saga familiale. Kimia, la narratrice, vit aujourd'hui à Paris. Patientant dans une salle d'attente, ce moment en suspend lui permet de revenir sur l'histoire de sa famille sur quatre générations. En toile de fond, I'Iran auXXe.J'ai construit le roman de façonàce que chacun des personnages ait un lien important avec un moment de son histoire. Cela part de l'arrière-grand-père. II donne sa fille en mariage au moment de la révolution constitutionnelle au début du XXe qui a fournit au parlement une constitution et une assemblée d'élus. Puis, la grand-mère connaît l'ascension de la famille Pahlavi. La ville où elle vit est celle où a été fomenté le coup d'État au cours duquel Reza Chah a pris le pouvoir. On passe par la suite au couronnement de son fils dans les années 1960. Avant cela, le père de la narratrice prend en charge, depuis la France, le récit du coup d'État fomenté par les Américains en 1953 pour destituer le régime de Mohammad Mossadegh. Le couronnement du Chah correspond à la naissance de l'une des filles. Les parents, opposants au régime du Chah, vont vivre la révolution.

\section{H\&M : Ce roman à caractère autobiogra- phique est intriqué avec l'histoire de l'Iran contemporain. Vous donnez l'impression, par les notes sous le texte, que vous antici- pez la méconnaissance de l'histoire iranienne chez les Français ?}

N. D. : Je pense que les Français sont peu informés de l'histoire de l'Iran en général. Même s'il s'agit d'un pays dont on entend parler tous les jours, il reste méconnu. Les Iraniens se pensent très francophiles, très proches de la France, mais cela n'est peut-être pas réciproque... Au fur et à mesure de mes rencontres, et des années passées en France et ailleurs, j'entends toujours parler de la Perse, donc de Darius et de Cyrus... puis, d'un coup, de la révolution de 1979. Quand je dis que ma mère portait un bikini sur les plages du Nord, on me regarde avec de grands yeux. C'est aussi l'une des raisons pour lesquelles j'ai écrit ce livre faire connaître l'histoire de ce pays et la façon dont est née cette révolution. Cette dernière ne répond pas à la volonté d'un peuple de réclamer I'islam au pouvoir, mais puise son origine dans le coup d'État qui a eu lieu en 1953. Pour la première fois, avant Cuba, les Américains avaient destitué le régime d'un autre pays. Les racines de cette 


\section{LITTÉRATURE}

révolution sont sans doute là. Mon désir d'écriture aussi.

L'exil de cettefamille est particulier puisqu'il n'ya pas de retour possible. Chacun vit cette situation à sa manière. On ne laisse pas derrière soi les mêmes choses selon son âge, ses urgences, ses inquiétudes. De fait, les personnages ne se situent pas dans l'entre-deux de l'immigration, où l'on arrive pas à bien se définir et qui peut durer plusieurs générations.Cet exil-là, très radical, très dur, très tranché au départ, pousse chacun à se positionner, à faire un choix.

\section{H\&M : Les trois sœurs ne vivent pas de la même façon leur arrivée en France. Certaines éprouvent une forme de désillu- sion, presque d'anéantissement, d'autres vont, au contraire, pouvoir se redéfinir, se redéployer. La protagoniste du roman en finit-elle avec l'exil ?}

N. D. : Elle fait quelque chose que ses sœurs ne font pas. Ces dernières déploient dans l'exil une énergie permettant de se dépasser, d'obtenir des diplômes, de fonder des familles, de s'intégrer par les études et la connaissance... ce qui est le cas de nombreux exilés et écrivains. Kimia, la narratrice,va faire de son exil une errance. Elle quitte l'exil pour entrer dans l'errance. Laissant derrière soi cette tragédie familiale que constitue l'exil, elle prend la route. C'est comme ça qu'elle parvient à se retrouver.Appartenir à nulle part, c'est appartenir à partout...

\section{H\&M : Votre narration alterne sans cesse entre des périodes et des lieux différents. Que représente l'usage de cette forme d'écriture si flexible?}

N. D. : Virginia Woolfentrait dans la tête des personnages. Avec Mrs. Dalloway, elle avait inauguré ce genre d'écriture du flux de la conscience, où l'on rentre dans la tête des personnages.Cela s'est imposé à moi car je ne vais pas en Iran. Je suis dans le cas de Kimia : je suis en exil strict.Je ne peux doncécrire que sur la mémoire. Même si Kimia n'est pas moi, même si je n'ai pas vécu son errance ni son expérience dans la salle d'attente, nous avons cela en commun : nous ne pouvons nous appuyer que sur notre mémoire. Et la mémoire fonctionne de cette manière-là. Par bribes. On raconte une histoire et soudain une autre apparaît... On parle d'un personnage et un autre surgit derrière... Dès le départ, je savais que je ne pourrais pas, pour être honnête avec moi-même, faire autrement que d'écrire de façon éclatée.

\section{H\&M : Comment votre manuscrit a-t-il été publié ?}

N. D. : Je l'ai envoyé aux éditions Liana Levi par email.J'ai eu cette chance incroyable que Liana Levi m'appelle une dizaine de jours plus tard. Je pense que je vis toujours sur la surprise de ce moment-là, dont tout le reste découle. Nous avons échangé ensemble. Puis j'ai travaillé avec Sandrine Thévenet, mon éditrice, au plus près du texte. Si rien n'a été modifié de son architecture, nous avons densifié, fait du montage.

\section{H\&M : Beaucoup d'Iraniens et d'Iraniennes publient en langue française. Quelle a été la réception de la sortie de votre ouvrage ?}

N. D. : C'est vrai qu'il y a énormément d'écrivains iraniens ou d'écrivaines qui ont écrit en français. Autant la poésie en Iran, depuis des siècles, est dans les mains des hommes, autant les femmes se sont emparées de la littérature. Celles qui ont écrit sur I'Iran depuis la France l'on fait pour une large part sur les conditions de la femme iranienne après la révolution. Cela n'est pas le cas de Désorientale, qui revient en arrière et tente d'écrire cet autre Iran. Celui des années 1960-1970. Et c'est peut-être cela qui a intéressé le public.Ce regard neuf que ne peut proposer que la littérature et qui permet de rencontrer des personnages, d'entrer dans leur vie, mais aussi de connaître des morceaux de ce pays, et de le voir différemment. Dans les rencontres auxquelles je participe, je vois que cela fonctionne. Les gens découvrent une autre réalité de l'Iran. I 